\title{
Google Maps Security Concerns
}

\author{
Aqil Burney', Muhammad Asif', Zain Abbas³, Shamaila Burney4 \\ ${ }^{1}$ Department of ASRM, College of Computer Science and Information Systems, IoBM, Korangi Creek, Karachi, Pakistan \\ ${ }^{2}$ Department of Computer Science \& Information Technology, NED University of Engineering \& Technology, Karachi, Pakistan \\ ${ }^{3}$ Department of Computer Science (UBIT), University of Karachi, Karachi, Pakistan \\ ${ }^{4}$ Department of Management Sciences, Hamdard University, Karachi, Pakistan \\ Email: aqil.burney@iobm.edu.pk, asifashrafiubit@hotmail.com, zain@uok.edu.pk, shamaila.burney@hamdard.edu.pk
}

How to cite this paper: Burney, A., Asif, M., Abbas, Z. and Burney, S. (2018) Google Maps Security Concerns. Journal of Computer and Communications, 6, 275-283. https://doi.org/10.4236/jcc.2018.61027

Received: December 3, 2017

Accepted: January 5, 2018

Published: January 8, 2018

Copyright $\odot 2018$ by authors and Scientific Research Publishing Inc. This work is licensed under the Creative Commons Attribution International License (CC BY 4.0).

http://creativecommons.org/licenses/by/4.0/

\section{Abstract}

Google Maps and other such maps in GIS have a lot of significance in every one's life for in modern world due to technological development as well as contemporary needs in travelling, business planning, agriculture, e-marketing supply chain management, census and planning and excessive use of mobile phones. Being a revolutionary technology, it attracts the users from its inception. It has been revolutionary in having an impact on one's daily life by helping one explore geographical locations virtually anywhere on the whole planet. It has become a norm that people use Google Maps before or while commuting to a certain place as most of the people rely on it to provide the shortest or fastest route to a destination. Google Maps has had a profound impact not only one's personal life, but has opened new avenues of marketing, business intelligence, urban planning, infrastructure strategy development, as well as traffic engineering. Hence, no one can deny the impact it has had on our society in a short period. However, Google Maps has security concerns associated with its use. This is because whenever a user is searching for a geographical location on Google Maps, there is no way to ascertain his/her intention. As result, whatever is requested by the user, it is provided without much security checks or personal specific logging history. Criminal minded people may use the technology to carry out unwarranted and uncalled-for activities such as terror attacks, exploitation of military assets, target killing, trailing a potential victim, kidnapping, demanding ransom money, and compromising national security etc. Numbers of such activities may be carried out using the guidance from "Google Maps" without getting noticed. This is largely due to that anonymous login is allowed into Google Maps. The paper highlights the main security issues that exist in the use of Google Maps and suggests the key areas to improve upon. In this research paper, we discuss the security concerns related to Google Maps utilization and try to identify the associated risks that may be worst in some situations due to that it is significant to assess 
the usage of this tremendous technology. We categorize the millions of Anonymous Google Maps users into two major categories (Anonymous Good Users and Anonymous Bad Users) based on Google Maps browsing and analyze the associated risks and potential threats and propose the way to minimize them. In future, if Google Maps adopts the proposed techniques and improves upon, then its utilization minimizes security concerns and makes the world much safe place.

\section{Keywords}

Google Maps, Anonymous Users, Cybercrime, Security Issues, Security Concerns, Spatial Information, Signup Mechanism, Potential Threats

\section{Introduction}

The Google Maps mashup is a very twenty-first-century beast born of code from disparate Web applications [1]. Mashups are product of Web 2.0 and attract both industry and academia. They represent an ad hoc composition technology of Web applications that allows users to utilize the content retrieved from external data sources and create entirely new services [2] [3]. Google Maps has been making profound impact on human life for a while now [4]. It helps people visit places, literally throughout the world, easily even though they aren't aware of those places or haven't visited them previously. In past, it was quite difficult to travel to any place if you are not aware of its location. Not anymore. Google Maps is there to help while you are driving a car, aboard a public transit, or riding a bike; simply using Google Maps to direct you to your desired location [5]. Moreover, it provides other details such as time to your destination, distance remaining, traffic situation, bus routes, etc. that can be used for making efficient decisions [6]. It also helps businesses in terms of marketing by classifying them into restaurants, shopping centers, picnic places, coffees shops, travel industries, rent-a-car, fuel pumps, workshops, hotels, private hospitals etc. [7]. Similarly, there are many other businesses that earn substantial marketing exposure due to the Google Maps technology.

As a result, millions of users interact with Google Maps daily to draw advantage. This usage generates huge history logs that can be used to improve user experience. The users discussed thus far are law abiding citizens who do not have any ulterior motives that use the services anonymously. But what about the people who use these services to carry out some suspicious agenda? There are terrorists, mafia, extortionists, and robbers etc. who have bad intentions and use Google Maps for carrying out their ulterior motives such as collecting sensitive information regarding Military, Law Enforcing Agencies, Government Departments, Sensitive public places, Sensitive installations, and others. They can use this information to breach the security of such places [8], so careful thought must be put in to address these issues to prevent negative usage of Google Maps 
by criminal minded users and avoid compromising the physical security of highly sensitive areas.

The rest of the paper is organized as follows.

\section{Google Maps Application}

It is a great technological advancement all over the world that helps millions of its users in getting quality geographical information for finding paths, locations, places, distances, required time to travel at specific place, and making rational decisions on the behalf of provided information. It has totally changed the way of thinking and decision making on a large scale of a common user in an effective manner. It has caused exponential growth for businesses worldwide; millions of users interact with it on daily basis for exploring different places. It has also helped tourism industry of all the countries by providing detailed insights, reviews and much more that enable easy access to those locations that remained hidden in the past.

\section{Google Maps Users and Classification}

After the commencement of Google Maps Technology millions of users are utilizing this technology on daily basis for finding different geographical locations and reduce time consuming tasks such as finding path, time required to reach at destination, total distance, transit travel, etc. by this technology. As in result, millions of users spend their time on Google Maps. Moreover, these users are anonymous for Google Maps because there is no requirement of user authentication or authorization such as login, session logs, or security verification. Hence, millions of users are still anonymous for google and their intentions are not known [9].

Figure 1 shows that users of Google Maps can be classified into two major categories basis on utilization of Google Maps technology:

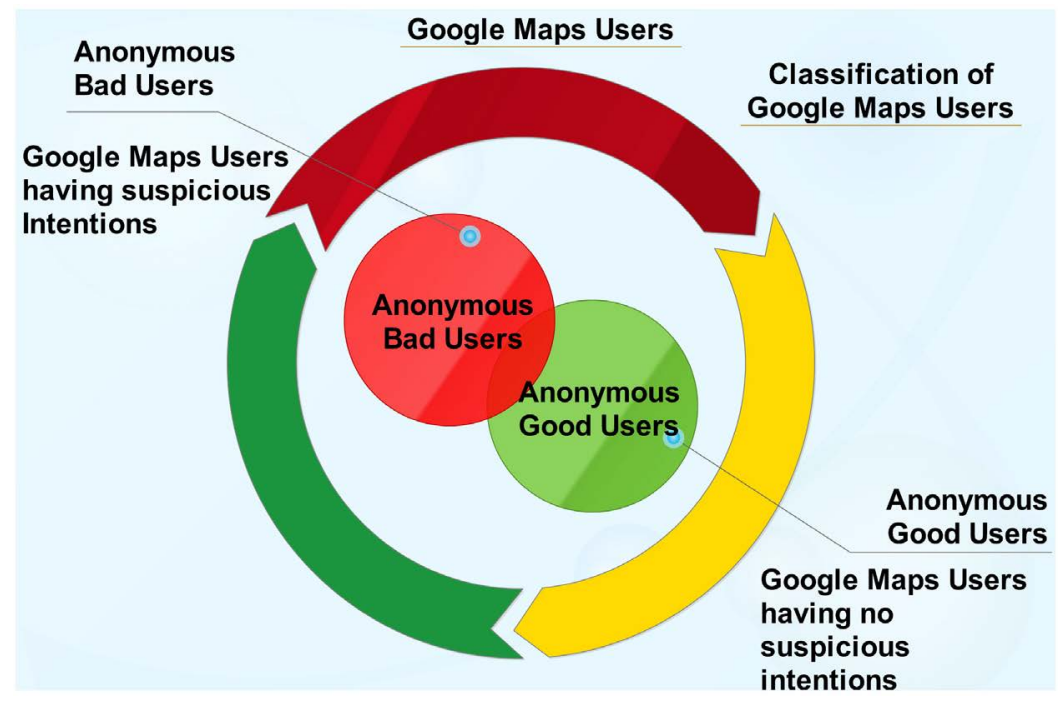

Figure 1. Google Maps users. 
- Anonymous Good User;

- Anonymous Criminal User.

Succeeding headings and diagrams will be helpful to understand the categories of anonymous users.

\subsection{Anonymous Good Users}

Google Maps users who are searching for places and have desire to get information regarding their needs that can be helpful to travel as well as getting know how and other related information regarding specific place having no suspicious thoughts. Such users do not pose any real threat or risk as they are not intending to achieve anything wrong. Similarly, they are not compromising the physical security of the high-profile places like government departments, secured army facilities, or other sensitive places that pertain to national interest. These kinds of users do not deal any further study or investigation they are generally "good" users. Figure 2 shows the classification of anonymous good users so potential risks are not associated with this sort of Google Maps users.

\subsection{Anonymous Bad Users}

A Google Maps user who is searching for a place with criminal intentions and desire to achieve suspicious activity is classified as an Anonymous Criminal User [10]. These users search for information that can be helpful for getting sensitive insights regarding places that may compromise security of governmental departments, military installations, and facilities relating to national security of a country. Moreover, such users may use maps to their advantage in carrying out nonsocial activities such as demanding ransom money in acts of kidnapping, murder or target killing. These horrendous acts can be executed after collecting location/route information from maps [11], without being noticed as Google Maps allows access from any place without being verified. Similarly, Google Maps doesn't take any details of its users and doesn't make any history logs for such anonymous users who are cyber criminals [12]. They pose real threat for

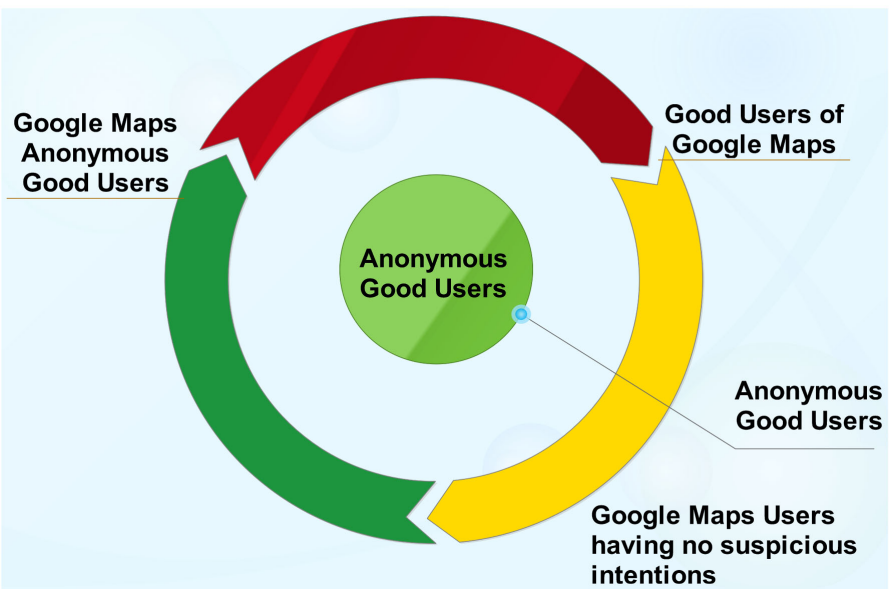

Figure 2. Anonymous good users. 
the national security of not only countries [13], but also societies, communities and common peoples. Hence, they should be dealt in efficient manner. Ways to ensure rational browsing regarding locations, neighborhoods and sensitive places etc. are discussed consequently. Figure 3 shows anonymous bad users.

\section{Google Maps Should Adopt}

A proposed way for Google Maps is to initiate authenticated sign up mechanism [14], for all users after getting necessary credentials during signup process. This will allow Google Maps to maintain the associated records \& credentials of each user along with session information, access location, browsing history, searching of places etc. into Google Maps databases which can be used for monitoring \& analyzing later, if it is required conditionally. Figure 4 shows signup process that can be helpful for neutralizing potential risks.

\section{Initiate Sign up Process}

Google Maps should introduce the sign-up process as shown in Figure 4 to users before browsing and searching any location. It should be mandatory to be registered a user after providing necessary credentials to Google Maps so that a user can be authenticated every time [14]. Whenever a user wants to search a location he or she must login through the same credentials as a legitimate user.

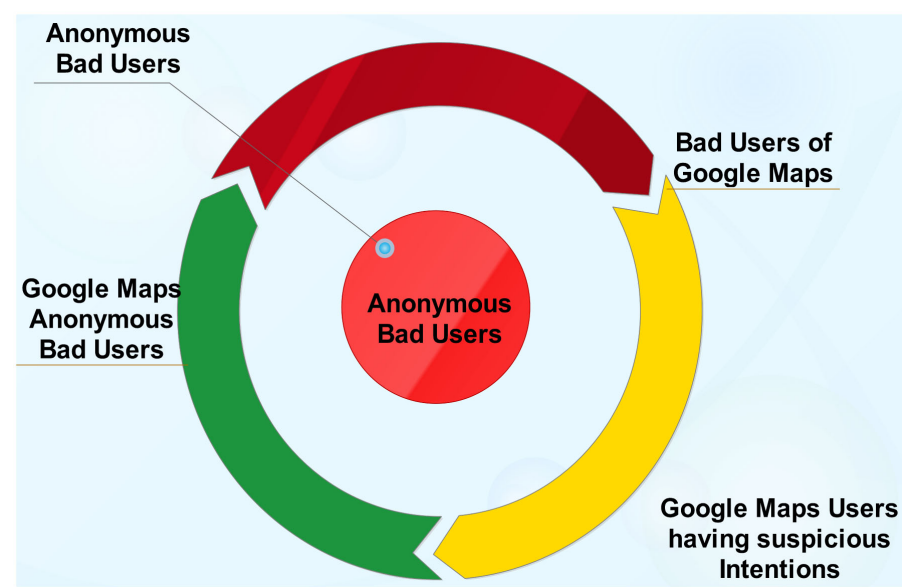

Figure 3. Anonymous bad users.

\section{Sign Up Process for \\ Neutralizing \\ Potential Bad Users}

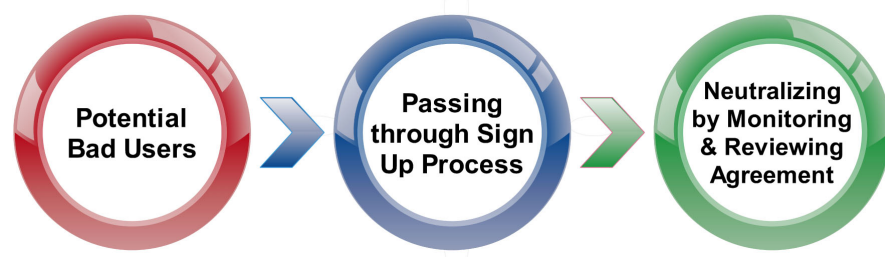

Figure 4. Sign up process. 


\section{Monitoring \& Reviewing Agreement}

Google Maps should take acceptance from users on Monitoring \& Reviewing agreement and warn to users regarding suspected browsing. If user browses a location that is highly sensitive, then user's activities can be monitored and reviewed. These may include acquiring user information such as session information, session locations details, history logs, browsed places etc. for performing investigations by the law enforcing agencies if any untoward incident or act of terror happens at that location.

This will be helpful for identification of "Criminal Users" that has been remaining "anonymous" up till now. Such users will not remain "anonymous" when Google Maps ensures that whoever wants to use Google Maps, must provide necessary credentials such as e-mail address and mobile numbers etc. consequently it will be extremely useful in tracking those criminal users who have bad intensions to violate physical security of highly sensitive area or having some suspicious intensions to disrupt the society.

\section{Potential Threats of Anonymous Users}

Millions of users of Google Maps utilize the assistance provided by this outstanding technology in everyday life and get better solutions of their problems for identifying any location as per their requirements. But, as already mentioned, many potential threats in form of criminal users having bad intensions, achieve their goals without being noticed. Since its inception, such users are utilizing this technology for malicious acts. We can see terrorist acts are happening all around the World and the overall security has been compromised due to ill mindsets, they use modern technologies including Google Maps for their worse intends. Moreover, terrorists may collect vital spatial details prior to carrying out an offensive at sensitive locations. As in result, such incidents also fall into the category of cyber terrorism.

\section{Distinctive Behaviors}

If any incident or act of terror occurs at specific highly sensitive location, then law \& enforcement agencies may get prompt assistance from Google Maps for assessing the history logs and identify those users who browsed for that specific location and gain vital spatial information from Google Maps. This information may lead to perform analysis and uncover their actual intensions as per browsing habits, history logs, and performing statistical and predictive analysis based on the available and accessible knowledge base. User's browsing pattern can be used to distinguish whether a user has positive intensions or negative intensions. Moreover, the ones marked as having ill intentions or past criminals can be monitored and remain on watch list by law enforcement agencies. Figure 5 shows that a potential bad user can be identified by browsing history and searching activities that can be used for predicting the risks and potential threats. 


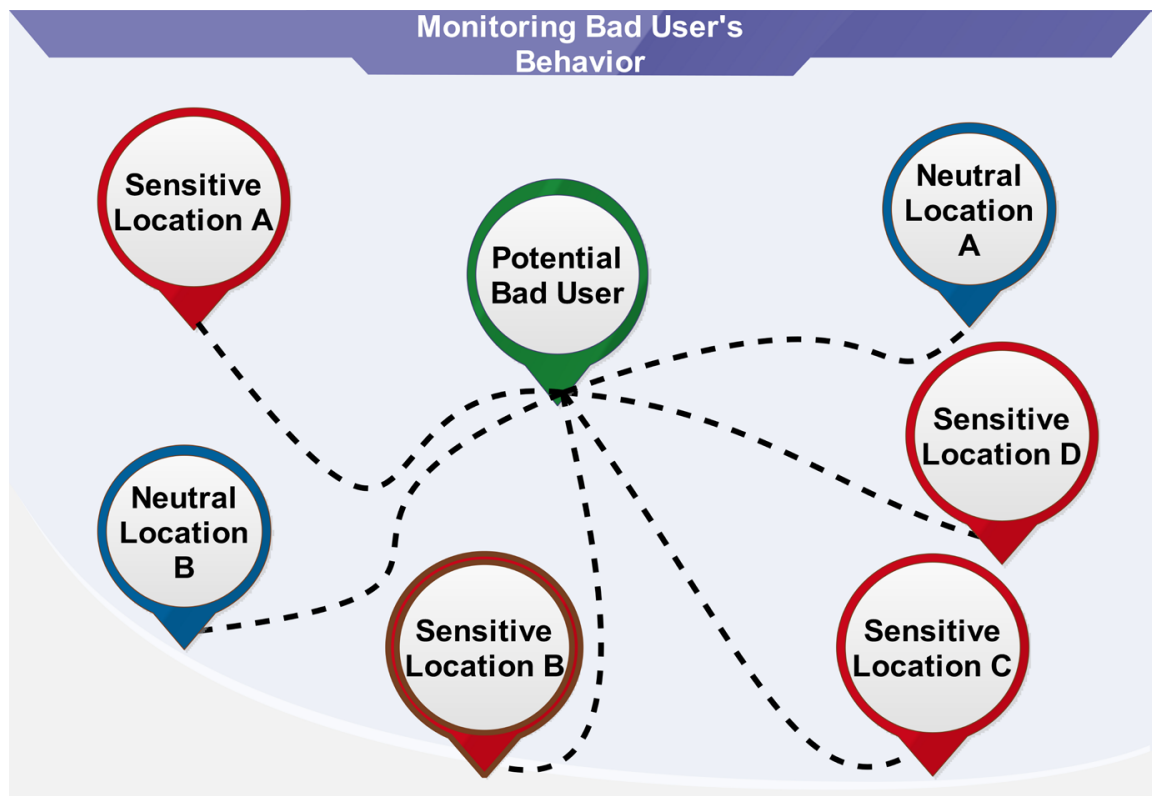

Figure 5. Monitoring user's behavior.

\section{Recommendations and Future Work}

In this paper, we have focused on security concerns relating to the use of Google Maps. We elaborated that millions of users using the technology are still anonymous and we are generally unaware of their intensions and motive behind the activities. As a result, they may accomplish their ulterior motives such as bomb blasts, target killing, mass shooting, high profile kidnapping, kidnapping for ransom etc. without being noticed. To cope with these challenges, main areas of future development should focus on the following:

1) Account creation must be mandatory for Google Maps Users.

2) Necessary credentials of the users must be filled in during the sign-up process.

3) Session logs, browsing history and activity logs must be maintained for each user.

4) Users must sign acceptance to terms and conditions that should include that in case of any suspected activity from the Google Map Account, legal actions can be taken against specific user.

5) In the result of signup process, millions of anonymous users will not further remain anonymous in future.

6) Google Maps must show warning pop ups to its users if he or she is trying to access any secure or sensitive place for browsing.

7) Statistical data analysis and predictive analytics can be used for predicting and judging the behavior of suspected user by applying these techniques on browsing history.

8) Learning mechanism in Artificial intelligence may be employed to mimic the behavior of a criminal user and potential malicious users of Google Maps may be forecasted. 
9) Cybercrimes acts can be used on Google Maps users if they are found guilty.

10) If any incident or act of terror happens at specific location, then browsing history of a user about that place can be reviewed and findings can be correlated with other available information for tracing criminals.

\section{Conclusion}

This research dealt with Google Maps Security Concerns related to Google Maps browsing, we focused on this great contemporary technology, it's importance, it's usage in every one's life, we classified millions of Google Maps users into two major categories: Anonymous Good Users and Anonymous Bad Users. We don't have (Security Risk) concern with good users but real concerns are criminal users, they are accomplishing their malicious intentions by utilizing this tremendous technology, we proposed different ways to deal with those criminal users, if any incident occurs then in what initiatives or ways to correlate a criminal user's activities by Google Maps browsing history for tracing criminals, we focused on security concerns of Google Maps, finally we recommended the future works such as signup mechanism that would enables Google Maps for getting necessary credentials such as user's contact details, country and city names, maintaining session logs will be helpful for identification of which device is used to access Google Maps and from which region it is used, history logs will be helpful for determining user's intensions such as using probabilistic methods, statistical methods, artificial intelligence \& knowledge based learning systems can be developed for predicting user's behavior \& tracing them for minimizing the associated risks and handling the security issues in appropriate manners in the real time for making rational decisions, consequently it would be a proactive approach for dealing with potential threats of cyberterrorism and terrorism because terrorism is a real issue all around the globe and we have a chance to set appropriate controls to mitigate the identified risk and threats for resolving the issues of "Google Maps Security Concerns".

\section{References}

[1] Miller, C.C. (2006) A Beast in the Field: The Google Maps Mashup as GIS/2. Cartographica: The International Journal for Geographic Information and Geovisualization, 41, 187-199. https://doi.org/10.3138/J0L0-5301-2262-N779

[2] Liu, X., Hui, Y., Sun, W. and Liang, H. (2007) Towards Service Composition Based on Mashup. 2007 IEEE Congress on Services, Salt Lake City, UT, 9-13 July 2007, 332-339. https://doi.org/10.1109/SERVICES.2007.67

[3] Hoyer, V. and Fischer, M. (2008) Market Overview of Enterprise Mashup Tools. International Conference on Service-Oriented Computing, Springer-Verlag, Berlin Heidelberg, 708-721. https://doi.org/10.1007/978-3-540-89652-4_62

[4] Dodsworth, E. and Nicholson, A. (2012) Academic Uses of Google Earth and Google Maps in a Library Setting. Information Technology and Libraries, 31, 102-117. https://doi.org/10.6017/ital.v31i2.1848 
[5] Belleau, F., Nolin, M.A., Tourigny, N., Rigault, P. and Morissette, J. (2008) Bio2RDF: Towards a Mashup to Build Bioinformatics Knowledge Systems. Journal of biomedical informatics, 41, 706-716. https://doi.org/10.1016/j.jbi.2008.03.004

[6] Pan, B., Crotts, J. C. and Muller, B. (2007) Developing Web-Based Tourist Information Tools Using Google Map. Information and Communication Technologies in Tourism, 2007, 503-512.

[7] Armstrong, G., Adam, S., Denize, S. and Kotler, P. (2014) Principles of Marketing. Pearson Australia.

[8] Saini, H., Rao, Y.S. and Panda, T.C. (2012) Cyber-Crimes and Their Impacts. International Journal of Engineering Research, 2, 202-209.

[9] Nguyen, L. (2014) User Model Clustering. Journal of Data Analysis and Information Processing, 2, 41-48. https://doi.org/10.4236/jdaip.2014.22006

[10] Rababah, O.M., Al Hwaitat, A.K., Al Manaseer, S., Fakhouri, H.N. and Rababah, O.M. (2016) Web Threats Detection and Prevention Framework. Communications and Network, 8, 170-178. https://doi.org/10.4236/cn.2016.83017

[11] Phipps, A.G. (2014) Three Applications of V.3 Google Maps: Just for Display of Data, or Analysis as Well? Journal of Geographic Information System, 6, 548-558. https://doi.org/10.4236/jgis.2014.65045

[12] Ahmad, R., Yunos, Z., Sahib, S. and Yusoff, M. (2012) Perception on Cyber Terrorism: A Focus Group Discussion Approach. Journal of Information Security, 3, 231-237. https://doi.org/10.4236/jis.2012.33029

[13] Alqahtani, A. (2014) Awareness of the Potential Threat of Cyberterrorism to the National Security. Journal of Information Security, 5, 137-146.

https://doi.org/10.4236/jis.2014.54013

[14] Ahmad, W., Zia, A. and Khalid, U. (2013) A Google Map Based Social Network (GMBSN) for Exploring Information about a Specific Territory. Journal of Software Engineering and Applications, 6, 343-348. https://doi.org/10.4236/jsea.2013.67043 